Tropical Journal of Pharmaceutical Research February 2021; 20 (2): 293-299

ISSN: $1596-5996$ (print); 1596-9827 (electronic) (C) Pharmacotherapy Group, Faculty of Pharmacy, University of Benin, Benin City, 300001 Nigeria

\title{
Neuroprotective effects of crude extract of Crataegus songarica on a rat model of traumatic brain injury
}

\author{
Xueliang Gao, Zhao Wang, Peilei Jia, Yapeng Zhao, Kai Wang, Puyang Li, \\ Jianye Cheng, Lipeng Qin, Zengbin Fu* \\ Department of Neurosurgery, Hebei Hospital of Traditional Chinese Medicine, Shijiazhuang, Hebei 050011, China
}

*For correspondence: Email: fuzb123@163.com; Tel: 0086-0311-69095611

Sent for review: 20 September 2020

Revised accepted: 24 January 2021

\begin{abstract}
Purpose: To investigate the protective effect of Crataegus songarica extract (CSCE) against traumatic brain injury (TBI) in rats, and the underlying mechanism of action.

Methods: $A$ rat model of TBI was established via tracheal intubation procedure, and the rats were treated with graded doses of CSCE. Neuronal survival was determined by Niss/ staining, while neuronal apoptosis was measured using TUNEL-staining. Neurological impairments were determined based on neurological severity score (NSS).

Results: Treatment of TBI rats with CSCE enhanced neuronal survival and decreased TUNEL-positive cell fraction in the brain cortex. The treatment prevented elevation of NSS and suppressed mRNA and protein expression levels of IL-6 and TNF- $\alpha$ in brain cortex. Moreover, CSCE treatment prevented TBImediated suppression of activities of superoxide dismutase (SOD) and glutathione peroxidase (GPX), and attenuated hydrogen peroxide $\left(\mathrm{H}_{2} \mathrm{O}_{2}\right)$ levels in TBI rat brain cortex. Treatment of TBI rats with CSCE down-regulated NF-KB expression, increased Nrf2 expression and up-regulated mRNA expressions of heme oxygenase 1 (HO- 1) and quinine oxidoreductase 1 (NQO- 1).

Conclusion: These results suggest that CSCE prevents TBI-mediated reduction in neuronal survival and inhibits brain cortical neuronal death in rats. It improves NSS and inhibits inflammatory response via activation of Nrf2 pathway and targeting of NF- $\kappa B$ expression. Therefore, CSCE is a potential therapeutic agent for TBI.
\end{abstract}

Keywords: Crataegus songarica, Traumatic brain injury, Neurological severity score, Interleukins

This is an Open Access article that uses a fund-ing model which does not charge readers or their institutions for access and distributed under the terms of the Creative Commons Attribution License (http://creativecommons.org/licenses/by/4.0) and the Budapest Open Access Initiative (http://www.budapestopenaccessinitiative.org/read), which permit unrestricted use, distribution, and reproduction in any medium, provided the original work is properly credited.

Tropical Journal of Pharmaceutical Research is indexed by Science Citation Index (SciSearch), Scopus, International Pharmaceutical Abstract, Chemical Abstracts, Embase, Index Copernicus, EBSCO, African Index Medicus, JournalSeek, Journal Citation Reports/Science Edition, Directory of Open Access Journals (DOAJ), African Journal Online, Bioline International, Open-J-Gate and Pharmacy Abstracts

\section{INTRODUCTION}

Traumatic brain injury (TBI) results from a blow to the head or piercing of brain tissue with a sharp-edged object, leading to impaired brain function [1,2]. Globally, TBI is responsible for millions of disabilities and billions of dollars in medical bills annually [3]. The extent of damage to nerves following $\mathrm{TBI}$ depends on whether primary or secondary injury is involved [4]. Primary injury refers to immediate damage following $\mathrm{TBI}$, while secondary injury comprises long-term injuries associated with oxidative stress, inflammatory reactions and neuronal apoptosis [2]. Oxidants and inflammatory factors play central roles in brain damage due to 
secondary injury [5]. Therefore, anti-oxidant strategies are believed to be of therapeutic significance in management of neuronal damage associated with TBI.

The NF-kB pathway is crucial in many inflammatory processes due to enhancement of TNF production, and release of interferons and interleukins during inflammation [6]. Inhibition of oxidative stress is stimulated by Nrf2 [7]. Nuclear factor erythroid 2-related factor 2 (Nrf2) is maintained in the cytoplasm during stress-free conditions and held with Kelch-like ECHassociated protein 1 (KEAP-1) [7]. Stress factors activate Nrf2 and promote expressions of cytoprotection-related proteins such as heme oxygenase-1 ( $\mathrm{HO}-1)$ and quinine oxidoreductase 1 (NQO-1) [8]. Cytoprotective proteins induce cellular resistance to stress initiated by oxidants [8]. Knockdown of Nrf2 at the genetic level has been found to promote severity of injury in mice with TBI via oxidative stress mechanism [9]. Therefore, NF-kB deactivation and Nrf2 upregulation serve as attractive targets for development of treatments for TBI.

Crataegus songarica berries have traditional medical significance in the treatment of congestive heart failure and arrhythmias, as well as improvement of cardiac output in patients with hypertension or pulmonary diseases [10]. Crataegus songarica is also used medicinally as a diuretic, antispasmodic and astringent [11]. The fruits of the plant are used for treating constipation, and for preventing epilepsy, hemorrhage, hypertension and asthma [11]. The present study was aimed at investigating the protective effect of Crataegus songarica extract (CSCE) against TBI, and the underlying mechanism of action.

\section{EXPERIMENTAL}

\section{Animals}

A total of sixty 7-week-old male Sprague-Dawley rats weighing 210 - $225 \mathrm{~g}$ were purchased from the Animal Centre of the Medical University, Nanjing, China. The rats were kept under standard conditions in an animal house at mean temperature $23 \pm 2{ }^{\circ} \mathrm{C}$ and $60 \%$ humidity in an environment with a 12-h light/12-h dark cycle. The rats were allowed free access to sterilized water and laboratory chow, and were acclimatized laboratory atmosphere for 1 week prior to the experiment. The study received approval from the Animal Care and Use Committee, Shijiazhuang, University, China. The animal experiments were conducted according to guidelines issued by the National Institute of Health, USA [12].

\section{Establishment of TBI rat model}

A stereotaxic frame was used for the establishment of TBI rat model [12]. The rats were anesthetized with chloral hydrate at a dose of $400 \mathrm{mg} / \mathrm{kg}$, and were put on the stereotaxic frame (David Kopf Instruments). A bone flap was removed by penetration of a portable drill into the right parieto-temporal cortex of each rat. A controlled impact was applied on the rat cortex using a pneumatic cylinder at a fixed velocity of $4 \mathrm{~m} / \mathrm{sec}$ and $1 \mathrm{~mm}$ depth. After the blow, the rat scalp was sutured under sterilized conditions. The rats were put back in cages and allowed to recover. Sham-treated rats were given same procedure except that no impact was applied on the cortical tissues. Rats in the treatment groups were given CSCE at doses of $1.5,3,6$, and 9 $\mathrm{mg} / \mathrm{kg}$ via intraperitoneal injection $2 \mathrm{~h}$ after TBI.

\section{Nissl staining}

The rats were anesthetized and sacrificed at 24 $h$ following $\mathrm{TBI}$, and subsequently perfused using normal saline. The rat brain tissues were excised fixed in $4 \%$ paraformaldehyde at $4^{\circ} \mathrm{C}$ for $24 \mathrm{~h}$, followed by paraffin embedding. Following deparaffinization, thin slices $(3-\mu \mathrm{m})$ of the tissues were put on slides coated with poly-Llysine for histopathological analysis. The sections were subjected to Nissl staining as per the manufacturer's instructions, and examined under a light microscope (Nikon Corporation).

\section{TUNEL staining and neurological impairment}

Presence of apoptotic cells in the brain cortex of rats was determined using an in situ cellular death detection kit (Catalog number: 1168481710; Roche Diagnostics). After paraffin embedding, $3-\mu \mathrm{m}$ thin tissue sections were deparaffinized, re-hydrated and subsequently washed in distilled water. Then, the tissues were digested with proteinase- $\mathrm{K}$ at room temperature for $20 \mathrm{~min}$, and washed and incubated in a humidifying box for $1 \mathrm{~h}$ at $25{ }^{\circ} \mathrm{C}$ with TUNEL mixture in the dark. Thereafter, the sections were washed and stained with DAPI before covering with coverslips and sealing. Fluorescence microscopy was used for examination of the TUNEL-stained cells in five different fields selected randomly. Cell quantification was done using Integrated Performance Primitives v9.0 software. Neurological severity score (NSS) was determined on a 10-point scale [12]. 
Determination of levels of IL-6, SOD, GPx, $\mathrm{H}_{2} \mathrm{O}_{2}$ and TNF- $\alpha$

The brain cortical tissues of rats were homogenized and centrifuged for $20 \mathrm{~min}$ at $12,000 \mathrm{~g}$. The supernatants were transferred to 96-well plates coated with anti-IL- 6, anti-SOD, anti-GPx, anti- $\mathrm{H}_{2} \mathrm{O}_{2}$ and anti-TNF- $\alpha$ monoclonal antibodies, and incubated for $95 \mathrm{~min}$ at $37^{\circ} \mathrm{C}$. This was followed by incubation with biotinlabelled secondary antibodies against SOD, GPX and $\mathrm{H}_{2} \mathrm{O}_{2}$ for 70 min at $37^{\circ} \mathrm{C}$. The supernatants were then incubated with 3,3'5,5tetramethylybenzidine for $30 \mathrm{~min}$ at $37^{\circ} \mathrm{C}$, after which optical density was read at $455 \mathrm{~nm}$ using a microplate reader.

\section{Western blot analysis}

The brain cortical tissues of rats were lysed using RIPA buffer, followed by protein extraction using protein extraction kit (Beyotime). The protein content of each lysate was estimated using BCA assay kit (catalog number: P0012s; Beyotime) in accordance with manufacturer's instructions. Total protein samples $(70-\mu \mathrm{g})$ were loaded per lane and subjected to $10 \%$ SDSpolyacrylamide gel electrophoresis, followed by transfer to PVDF membranes (EMD Millipore). The membranes were blocked by incubation with $5 \%$ skimmed milk for $2.5 \mathrm{~h}$ at $25{ }^{\circ} \mathrm{C}$. Thereafter, the membranes were incubated overnight at $4^{\circ} \mathrm{C}$ with primary antibodies against Nrf2 $(1: 1,000)$, NFKB $(1: 1,000)$ and $\beta$-actin $(1: 3,000)$. Thereafter, the membranes were rinsed in TBS and Polysorbate20, after which they were incubated for $1.5 \mathrm{~h}$ with secondary antibodies at room temperature. Visualization of protein bands was made using enhanced chemiluminescence system (catalog number P0018AS; Beyotime) connected to imaging system (Bio- Rad Laboratories, Inc.).

\section{Reverse transcription quantitative PCR (RT- qPCR)}

Total RNA was extracted from the rat cortical tissues was using TRIzol reagent (Invitrogen). The total RNA concentration was determined with protein analyzer (Beckman Coulter, Inc.), followed by reverse-transcription to circular DNA

Table 1: Primer sequences used in RT-PCR using Prime Script RT- PCR kit (Takara Bio, Inc.) as per the supplier's instructions. The qPCR was performed using Eppendorf Real Plex-4 instrument linked to real-time SYBR Green (Bio- Rad Laboratories, Inc.). The thermocycling sequence was: $93^{\circ} \mathrm{C}$ for $8 \mathrm{~min}$, and then 39 cycles of $93{ }^{\circ} \mathrm{C}$ for $12 \mathrm{sec}$, followed by $58{ }^{\circ} \mathrm{C}$ for $90 \mathrm{sec}$. The relative mRNA expression levels were quantified using the 2${ }^{\Delta} \mathrm{C} \mathrm{Cq}$ method. The primer sequences used are indicated in Table 1.

\section{Statistical analysis}

Data are expressed as mean \pm standard error of mean for three experiments. Statistical analysis was done using GraphPad Pro 5.0 (GraphPad Software, Inc.). Differences between two groups were determined using Student's $t$-test, while multiple group comparison was done with analysis of variance (ANOVA), followed by Dunnett's post hoc test. Differences were taken as statistically significant at $p<0.05$.

\section{RESULTS}

\section{CSCE suppressed neurofunctional deficits in the rat model of TBI}

Nissl-positive staining was significantly decreased in rats following TBI, compared to rats in sham group $(p<0.05$; Figure 1 A). However, treatment of TBI rats with CSCE led to dose-dependent increases in neuronal survival, as was evident in significantly higher count of Nissl- positive stained cells. In TBI rats, there was marked enhancement in the fraction of TUNEL-positive cells, when compared to the sham group $(p<0.05$; Figure $1 \mathrm{~B})$. However, the CSCE treatment suppressed increase in TUNEL-positive cell fraction in TBI rats, relative to model TBI group.

\section{CSCE suppressed NSS score and edema in rat model of TBI}

Rats in model TBI group showed significantly elevated NSS, relative to rats in the sham group $(p<0.05$; Figure $2 \mathrm{~A})$.

\begin{tabular}{lll}
\hline Gene & Forward & Reverse \\
\hline HO- 1 & 5'- ATC GTG CTC GCA TGA ACA CT- 3' & 5'- CCA ACA CTG CAT TTA CAT GGC- 3' \\
NQO1 & 5'- CAT TCT GAA AGG CTG GTT & 5'- CTA GCT TTG ATC TGG TTG TCA G- 3' \\
& TGA- 3' & \\
3- actin & 5'- CCG TGA AAA GAT GAC CCA GA- 3' & 5'- TAC GAC CAG AGG CAT ACA G- 3' \\
\hline
\end{tabular}




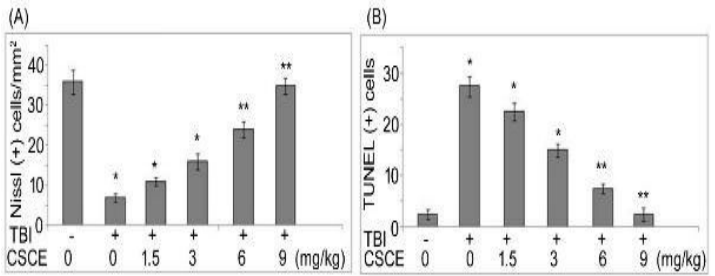

Figure 1: Effect of CSCE on survival of neurons in TBI rats. (A) Neuronal survival in TBI rats given CSCE at doses of $1.5,3,6$, and $9 \mathrm{mg} / \mathrm{kg} 2 \mathrm{~h}$ after TBI, and then subjected to Nissl staining at $24 \mathrm{~h}$ of TBI. (B) Cell death at $24 \mathrm{~h}$ of TBI, as determined with TUNELstaining of brain cortex. ${ }^{*} P<0.05 ;{ }^{* *} p<0.02$ vs. sham group

However, treatment of TBI rats with CSCE significantly and dose-dependently attenuated the TBI-induced increase in NSS $(p<0.05)$. The NSS was reduced to minimum at CSCE dose of $9 \mathrm{mg} / \mathrm{kg}$. Traumatic brain injury (TBI) also enhanced water accumulation in brain cortex of rats, relative to sham group (Figure $2 \mathrm{~B}$ ). However, CSCE treatment prevented water accumulation in the TBI rat brain tissues.

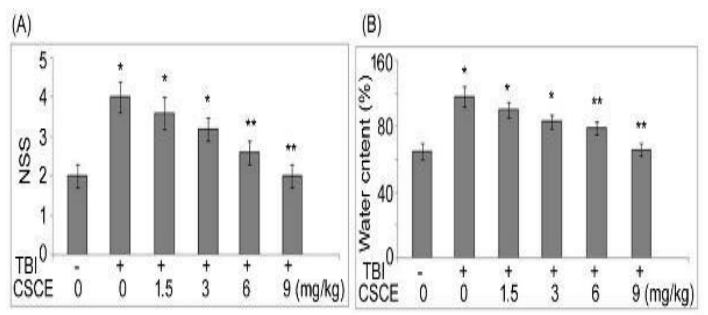

Figure 2: Effect of CSCE on NSS and water accumulation in brain cortex of $\mathrm{TBI}$ rats. (A) Neurological severity scores at $24 \mathrm{~h}$ of TBI in rats given CSCE at doses of $1.5,3,6$, and $9 \mathrm{mg} / \mathrm{kg} 2 \mathrm{~h}$ after TBI. (B) Water accumulation in brain cortex. ${ }^{*} P<$ $0.05 ;{ }^{* *} p<0.02$ vs. sham group

\section{CSCE reversed TBI-mediated inflammatory response}

The protein expression levels of IL- 6 and TNF$\alpha$ in rat brain cortex were markedly elevated by $\mathrm{TBI}$, relative to the sham group (Figure $3 \mathrm{~A}$ ). However, CSCE treatment suppressed TBIinduced up-regulation in protein expression levels of IL- 6 and TNF- $\alpha$ in the brain cortex, with CSCE dose of $9 \mathrm{mg} / \mathrm{kg}$ resulting in maximum suppressions in the levels of these parameters. Up-regulation of IL- 6 and TNF- $\alpha$ contents in rat brain cortex by TBI were also confirmed using RT-PCR assay (Figure 3B). The TBI-induced increases in MRNA expression levels of IL- 6 and TNF- $\alpha$ in rat brain cortex were dosedependently reduced by CSCE.

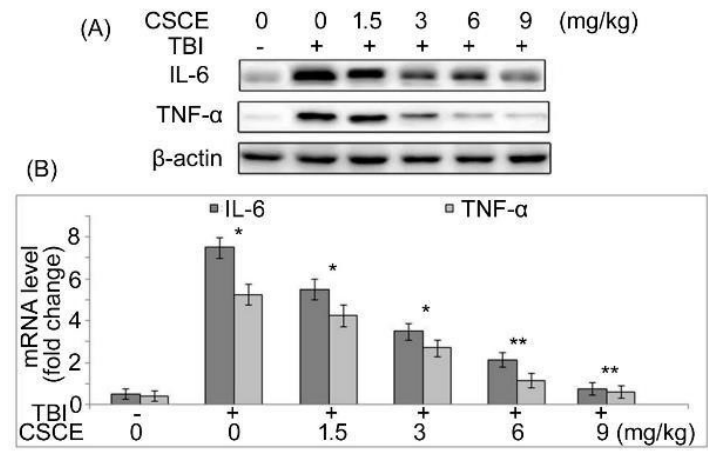

Figure 3: Effect of CSCE on mRNA and protein expressions of IL- 6 and TNF- $\alpha$ in TBI rats. (A) Protein expression levels of IL- 6 and TNF- $\alpha$ in rats given CSCE at doses of 3,6 , and $9 \mathrm{mg} / \mathrm{kg} 2 \mathrm{~h}$ after TBI, as assayed using western blotting. (B) Changes in mRNA levels of IL- 6 and TNF- $\alpha$ mRNA in TBI rats treated with CSCE, as determined using RT-PCR assay. ${ }^{*} P<0.05 ;{ }^{* *} p<0.02$ vs. sham group

\section{CSCE reduced TBI-mediated oxidative stress}

There were lower activities of SOD and GPx in brain cortex of $\mathrm{TBI}$ rats than in brain cortex of the sham group (Figure $4 \mathrm{~A}$ ). However, CSCE treatment at doses of 3,6 , and $9 \mathrm{mg} / \mathrm{kg}$ significantly prevented TBI-mediated suppression of SOD and GPx activities in the rat brain cortex. In TBI rats, the brain cortex showed significantly elevated content of $\mathrm{H}_{2} \mathrm{O}_{2}$, when compared to brain cortex of the sham group $(p<$ 0.05; Figure $4 \mathrm{~B}$ ). However, the TBl-induced elevation in $\mathrm{H}_{2} \mathrm{O}_{2}$ content in rat brain cortex was inhibited by CSCE in a dose-based manner, with a dose of $9 \mathrm{mg} / \mathrm{kg}$ resulting in the highest reduction in $\mathrm{H}_{2} \mathrm{O}_{2}$ content in brain cortex.

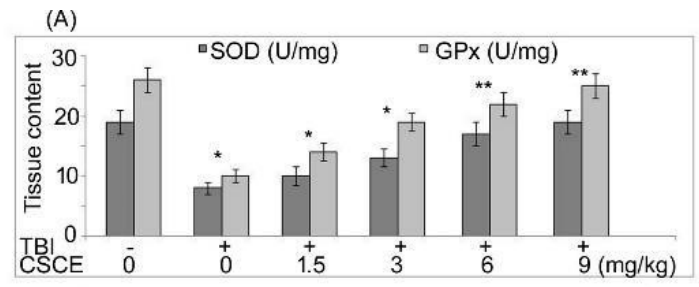

(B)

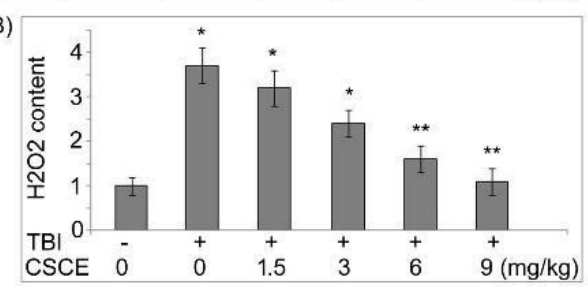

Figure 4: Effect of CSCE on oxidative stress in TBI rats. (A) Brain cortex activities of SOD and GPx in TBI rats given CSCE at doses of 3,6 , and $9 \mathrm{mg} / \mathrm{kg} 2 \mathrm{~h}$ after TBI. (B) Effect of CSCE on $\mathrm{H}_{2} \mathrm{O}_{2}$ content in brain cortex of TBI rats. ${ }^{*} P<0.05 ;{ }^{* *} p<0.02$ vs. sham group 
CSCE suppressed NF-KB expression in TBI rats

The expression of NF-KB was markedly upregulated in the brain cortex of TBI rats, when compared to sham group (Figure 5). However, treatment of the TBI rats with CSCE suppressed the cortical elevation of NF-KB expression in a dose-based manner. The CSCE treatment reduced NF-KB expression in brain cortex of the $\mathrm{TBI}$ rats to a minimum level at a dose of 9 $\mathrm{mg} / \mathrm{kg}$.

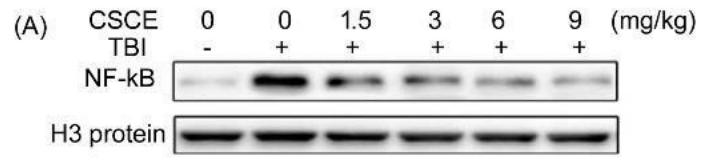

(B)

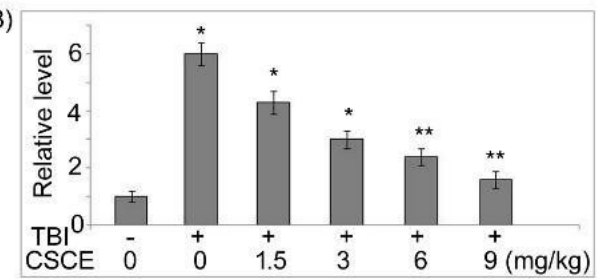

Figure 5: Effect of CSCE on NF-KB expression in TBI rats. (A) Protein expression level of NF-KB in brain cortex of TBI rats given CSCE at doses of 3,6 , and 9 $\mathrm{mg} / \mathrm{kg}$ doses) $2 \mathrm{~h}$ after TBI, as determined with western blotting. (B) Quantification of the NF-KB expression. ${ }^{*} P<0.05 ;{ }^{* *} p<0.02$ vs. sham group

\section{CSCE promoted Nrf2 expression in TBI rats}

Traumatic brain injury (TBI) caused a slight increase in Nrf2 expression in the brain cortex of rats, relative to sham group (Figure 6). However, CSCE treatment enhanced Nrf2 expression in the brain cortex of rats. The mRNA levels of HO1 and NQO-1 were also slightly elevated in brain cortex of the TBI rats. However, treatment with CSCE significantly up-regulated the expressions of HO-1 and NQO-1 in the brain cortex of TBI rats.

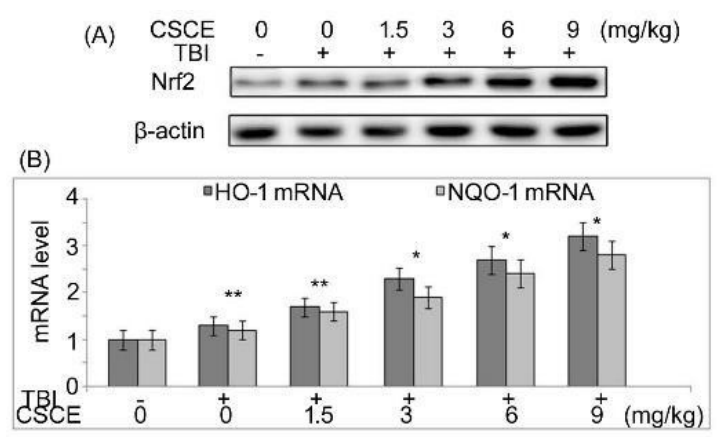

Figure 6: Effect of CSCE on Nrf2 expression in TBI rats. (A) Expression levels of Nrf2 in brain cortex of rats given CSCE at doses of 3,6 , and $9 \mathrm{mg} / \mathrm{kg} 2 \mathrm{~h}$ after TBI, as assayed using western blotting. (B) mRNA expression levels of $\mathrm{HO}-1$ and $\mathrm{NQO}-1$, as determined using RT-PCR. ${ }^{*} P<0.05 ;{ }^{* *} p<0.02$ vs. sham group

\section{DISCUSSION}

Traumatic brain injury (TBI) is a serious health issue that may result in permanent brain injury as well as several neurological disorders [13]. Secondary brain injury is accompanied by multiple processes such as activation of inflammatory response and excessive release of oxidative molecules [14,15]. Indeed, secondary injury associated with TBI leads to neurological disorders, disabilities and even death $[14,15]$. Non-availability of effective treatment strategies for TBI is responsible for development of secondary injury in most TBI patients. Thus, there is need for novel anti-TBI strategies.

The present study investigated the protective effect of Crataegus songarica extract (CSCE) against $\mathrm{TBI}$, and the underlying mechanism of action. The results demonstrated that CSCE treatment of TBI rats produced dose-based neuronal survival. This was evident in increased count of Nissl-positive cells. Moreover, TBI rats showed higher fraction of TUNEL-positive cells than cells in the sham group. However, CSCE treatment prevented the TBI-induced increase in TUNEL-positive cell fraction, relative to model TBI group. Moreover, CSCE dose-dependently suppressed TBI-induced elevation in the NSS score. Thus, CSCE prevented TBI-mediated decrease in survival, and inhibited neuronal death in brain cortex of TBI rats.

Inflammatory response, a prominent event in $\mathrm{TBI}$, is associated with activation of NF-KB [16]. Studies have shown that targeting the activation of NF-KB has beneficial effect on injuries induced by ischemia/reperfusion $[16,17]$. In the present study, TBI markedly enhanced NF-KB expression in the brain cortex of rats, when compared to sham group. Treatment of TBI rats with CSCE prevented elevation of NF-KB expression in the cortical tissues in a dosebased manner. It has been reported that hippocampal damage may be mitigated in pneumococcal meningitis animal model by therapeutic agents via targeting oxidative response through activation of the $\mathrm{Nrf} / \mathrm{HO}-1$ pathway [19]. In the present study, TBI caused a slight increase in Nrf2 expression in the brain cortex of rats, relative to sham group. However, CSCE treatment dose-dependently promoted Nrf2 expression in the brain cortex of rats. The levels of mRNA corresponding to HO-1 and

Trop J Pharm Res, February 2021; 20(2): 297 
NQO-1 were also slightly elevated in brain cortex of the rats following TBI.

However, treatment with CSCE significantly reversed this trend by up-regulating the mRNA and protein expressions of $\mathrm{HO}-1$ and $\mathrm{NQO}-1$ in the brain cortex of TBI rats. Moreover, CSCE treatment significantly reversed TBI-mediated suppression of activities of SOD and GPx in the rat brain cortex, at doses of 3,6 , and $9 \mathrm{mg} / \mathrm{kg}$. The TBI-induced elevation of $\mathrm{H}_{2} \mathrm{O}_{2}$ content in rat brain cortex was inhibited by CSCE in dosebased manner.

\section{CONCLUSION}

The findings of this study show that CSCE prevents TBI-mediated reduction in neuronal survival and inhibits brain cortical neuronal death in rats. It also improves NSS and inhibits inflammatory response through activation of Nrf2 pathway and targeting of the expression of NF$\mathrm{KB}$. Therefore, CSCE is a potential therapeutic strategy for TBI.

\section{DECLARATIONS}

\section{Conflict of interest}

No conflict of interest is associated with this work.

\section{Contribution of authors}

We declare that this work was done by the authors named in this article and all liabilities pertaining to claims relating to the content of this article will be borne by the authors. Xiu Xueliang Gao, Zhao Wang, Peilei Jia, Yapeng Zhao, Kai Wang, Puyang Li, Jianye Cheng and Lipeng Qin performed the experimental work, carried out the literature survey, and analysed and compiled the data. Zengbin $\mathrm{Fu}$ designed the study and wrote the paper. All the authors read the paper thoroughly and approved it for publication.

\section{Open Access}

This is an Open Access article that uses a funding model which does not charge readers or their institutions for access and distributed under the terms of the Creative Commons Attribution License (http://creativecommons.org/licenses/by/ 4.0) and the Budapest Open Access Initiative (http://www.budapestopenaccessinitiative.org/rea d), which permit unrestricted use, distribution, and reproduction in any medium, provided the original work is properly credited.

\section{REFERENCES}

1. Delbary Gossart S, Lee S, Baroni M, Lamarche I, Arnone M, Canolle B, Lin A, Sacramento J, Salegio EA, Castel MN. A novel inhibitor of p75 neurotrophin receptor improves functional outcomes in two models of traumatic brain injury. Brain 2016; 139: 17621782.

2. Scott G, Zetterberg $H$, Jolly A, Cole JH, De Simoni S, Jenkins $P O$, Feeney $C$, Owen DR, Lingford Hughes A, Howes $O$. Minocycline reduces chronic microglial activation after brain trauma but increases neurodegeneration. Brain 2018; 141: 459471.

3. Wang ZG, Cheng $Y, Y u X C, Y e L B$, Xia $Q H$, Johnson $N R$, Wei $X$, Chen DQ, Cao G, Fu XB. bFGF protects against blood brain barrier damage through junction protein regulation via PI3K Akt rac1 pathway following traumatic brain injury. Mol Neurobiol 2016; 53: 7298 7311.

4. Liu Z, Wang H, Shi X, Li L, Zhou M, Ding H, Yang Y, Li X, Ding K. $D L \quad 3 \quad n$ Butylphthalide (NBP) Provides Neuroprotection in the mice models after traumatic brain injury via Nrf2 ARE signaling pathway. Neurochem Res 2017; 42: 13751386.

5. Chen X, Wang H, Zhou M, Li X, Fang Z, Gao H, Li Y, Hu $W$. Valproic acid attenuates traumatic brain injury induced inflammation in vivo: Involvement of autophagy and the Nrf2/ARE signaling pathway. Front $\mathrm{Mol}$ Neurosci 2018; 11: 117.

6. Gupta SC, Sundaram C, Reuter S, Aggarwal BB. Inhibiting NF-KB activation by small molecules as a therapeutic strategy. Biochim Biophys Acta 2010; 1799: 775-787.

7. Fabrizio FP, Sparaneo A, Trombetta D, Muscarella LA. Epigenetic versus genetic deregulation of the KEAP1/NRF2 axis in solid tumors: Focus on methylation and noncoding RNAs. Oxid Med Cell Longev 2018; 2018: 2492063.

8. Tian A, Ma H, Zhang $R$, Cui $Y$, Wan C. Edaravone improves spatial memory and modulates endoplasmic reticulum stress- mediated apoptosis after abdominal surgery in mice. Exp Ther Med 2017; 14: 355-360.

9. Pan H, Wang H, Zhu L, Mao L, Qiao L, Su X. Depletion of Nrf2 enhances inflammation induced by oxyhemoglobin in cultured mice astrocytes. Neurochem Res 2011; 36: 2434-2441.

10. Holubarsch CJF, Colucci WS, Meinertz T, Gaus W, Tendera M. Survival and Prognosis: Investigation of Crataegus Extract WS 1442 in congestive heart failure (SPICE)—rationale, study design and study protocol. Eur J Heart Fail 2000; 2: 431-437.

11. Khan AA, Ashfaq M, Ali MN. Pharmacognostic Studies of selected indigenous plants of Pakistan. Pakistan Forest Institute, Peshawar. Pakistan 1979; 6: 7.

12. Choi YK, Maki T, Mandeville ET, Koh SH, Hayakawa K, Arai K, Kim YM, Whalen MJ, Xing C, Wang X. Dual effects of carbon monoxide on pericytes and neurogenesis in traumatic brain injury. Nat Med 2016; 22: 1335-1341.

Trop J Pharm Res, February 2021; 20(2): 298 
13. Bedi SS, Aertker BM, Liao GP, Caplan HW, Bhattarai D, Mandy F, Mandy F, Fernandez LG, Zelnick P, Mitchell $M B$. Therapeutic time window of multipotent adult progenitor therapy after traumatic brain injury. J Neuroinflammation 2018; 15: 84.

14. Lozano D, Gonzales-Portillo GS, Acosta S, de la Pena I, Tajiri N, Kaneko Y, Borlongan CV. Neuroinflammatory responses to traumatic brain injury: Etiology, clinical consequences, and therapeutic opportunities. Neuropsychiatr Dis Treat 2015; 11: 97-106.

15. Liu Y, Bao Z, Xu X, Chao H, Lin C, Li Z, Liu Y, Wang X, You $Y$, Liu N, Ji J. Extracellular Signal Regulated Kinase/ Nuclear Factor Erythroid2 like2/Heme Oxygenase 1 Pathway Mediated Mitophagy Alleviates Traumatic Brain Injury-Induced Intestinal Mucosa Damage and Epithelial Barrier Dysfunction. J Neurotrauma 2017; 34: 2119-2131.
16. Fujiwara $N$, Som AT, Pham LD, Lee BJ, Mandeville ET, Lo $E H$, Arai $K$. A free radical scavenger edaravone suppresses systemic inflammatory responses in a rat transient focal ischemia model. Neurosci Lett 2016; 633: 7-13.

17. Chiazza F, Chegaev K, Rogazzo M, Cutrin JC, Benetti E, Lazzarato L, Fruttero R, Collino M. A nitric oxide donor furoxan moiety improves the efficacy of edaravone against early renal dysfunction and injury evoked by ischemia/reperfusion. Oxid Med Cell Longev 2015; 2015: 804659.

18. Li Z, Ma QQ, Yan Y, Xu FD, Zhang XY, Zhou WQ, Feng ZC. Edaravone attenuates hippocampal damage in an infant mouse model of pneumococcal meningitis by reducing HMGB1 and iNOS expression via the Nrf2/HO 1 pathway. Acta Pharmacol Sin 2016; 37: 12981306. 